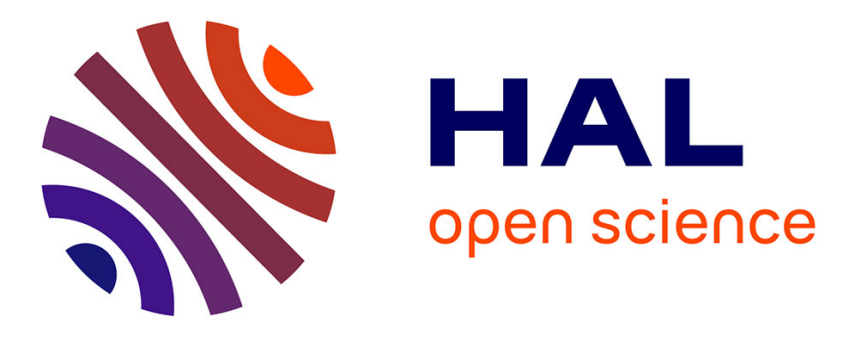

\title{
Logical and Evidential Inconsistencies Meet: First Steps
}

Nadia Ben Abdallah, Sébastien Destercke, Anne-Laure Jousselme, Frédéric

\author{
Pichon
}

\section{To cite this version:}

Nadia Ben Abdallah, Sébastien Destercke, Anne-Laure Jousselme, Frédéric Pichon. Logical and Evidential Inconsistencies Meet: First Steps. 6th International Conference on Belief Functions (BELIEF 2021), Sep 2021, Shanghai, China. pp.207-214, 10.1007/978-3-030-88601-1_21 . hal-03387904

\section{HAL Id: hal-03387904 https://hal.science/hal-03387904}

Submitted on 23 Nov 2021

HAL is a multi-disciplinary open access archive for the deposit and dissemination of scientific research documents, whether they are published or not. The documents may come from teaching and research institutions in France or abroad, or from public or private research centers.
L'archive ouverte pluridisciplinaire HAL, est destinée au dépôt et à la diffusion de documents scientifiques de niveau recherche, publiés ou non, émanant des établissements d'enseignement et de recherche français ou étrangers, des laboratoires publics ou privés. 


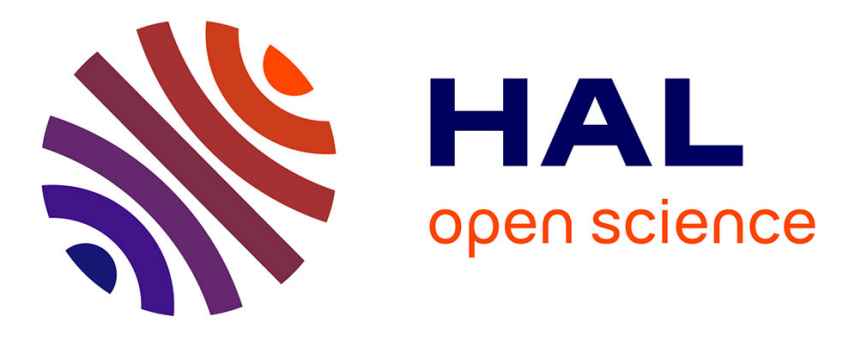

\section{Logical and Evidential Inconsistencies Meet: First Steps}

Nadia Ben Abdallah, Sébastien Destercke, Anne-Laure Jousselme, Frédéric

Pichon, University Machin

\section{To cite this version:}

Nadia Ben Abdallah, Sébastien Destercke, Anne-Laure Jousselme, Frédéric Pichon, University Machin. Logical and Evidential Inconsistencies Meet: First Steps. 6th International Conference on Belief Functions, Sep 2021, Shanghai, China. pp.207-214, 10.1007/978-3-030-88601-1_21 . hal-03387904

\section{HAL Id: hal-03387904 \\ https://hal.archives-ouvertes.fr/hal-03387904}

Submitted on 23 Nov 2021

HAL is a multi-disciplinary open access archive for the deposit and dissemination of scientific research documents, whether they are published or not. The documents may come from teaching and research institutions in France or abroad, or from public or private research centers.
L'archive ouverte pluridisciplinaire HAL, est destinée au dépôt et à la diffusion de documents scientifiques de niveau recherche, publiés ou non, émanant des établissements d'enseignement et de recherche français ou étrangers, des laboratoires publics ou privés. 


\title{
Logical and evidential inconsistencies meet: first steps
}

\author{
Nadia Ben Abdallah Sébastien Destercke Anne-Laure Jousselme Frédéric Pichon
}

\begin{abstract}
Measuring inconsistency has been and is still an active research topic in both logic and evidence theory. However, the two fields have developed distinct notions and measure of inconsistency, following different paths. In this paper, we attempt to build some first bridges between the two trends, suggesting some first means for one to enrich the other, and vice-versa.
\end{abstract}

Keywords: inconsistency, logic, belief functions

\section{Introduction}

Evidence theory (a.k.a. Dempster-Shafer theory, Belief function theory) and logic share many common concerns, and one of them is how to deal with inconsistency of information coming from multiple sources. For example, the notion maximal coherent subsets or its dual, minimal unsatisfiable subset, appear in both settings to deal with inconsistencies $[8,2]$.

One particular problem that has attracted a lot of attention in the two settings is how to measure inconsistency $[8,3,1,5]$. However, as the two fields commonly use different basic models and assumptions (e.g., in the way the set of possible worlds is generated), they have provided different answers to this issue.

Our goal in this paper is not to introduce new ways to measure conflict or inconsistency in belief function theory, as there is already an ample literature on the topic (the reader can check $[1,5,4]$, for instance). Our agenda is rather to explore what logic and belief functions theory can bring to each other when it comes to measure inconsistency. Similarly, while bridges between evidence theory and some logic frameworks such as penalty logic were studied before [7], the interconnections of the two settings when it comes to inconsistency is barely mentioned, let alone investigated.

In this paper, we mainly expose why we think tools issued from logic could be interesting for evidential reasoning and inconsistency quantification, and propose a simple way to use them within evidential reasoning. In particular, we think that measures of inconsistency issued from logic can help in identifying the main sources of observed inconsistency, a topic already explored within evidence theory [6], but never by using a logical perspective.

We start by detailing an example motivating the topic considered on this paper in Section 2, in which we also provide some notations used in the paper. 
Section 3 then makes a first simple, yet original proposal ${ }^{1}$ to embed inconsistency measures issued from logic within evidential reasoning.

\section{A motivational example}

In this section, we first introduce some notations, before detailing an example motivating the interest of using inconsistency measures within the framework of evidence theory.

\section{$2.1 \quad$ Needed notations}

We consider a finite propositional language $\mathcal{L}$. We denote by $\Omega$ the space of all interpretations of $\mathcal{L}$, and by $\omega$ an element of $\Omega$. Given a formula $\phi, \omega$ is a model of $\phi$ if it satisfies it, denoted $\omega=\phi$. We denote the models of a formula $\phi$ by $E_{\phi}$, that corresponds to usual subsets of $\Omega$, the set of all interpretations. For convenience and to recall that we are assuming that sets are models of propositional logic formulas, we will also sometimes denote by $\perp$ and $T$ the empty set $\emptyset$ and $\Omega$, respectively. Since there is no ambiguity in propositional logic, we will also confuse $\phi$ with its sets of models for convenience. A knowledge base $K B=\left\{\phi_{1}, \ldots, \phi_{n}\right\}$ is usually formed of a conjunction $\phi_{1} \wedge \ldots \wedge \phi_{n}$ of formulas.

We consider that uncertain information is modelled by mass functions, i.e., a non-negative and normalised mapping $m: \Omega \rightarrow[0,1]$ with $\sum_{E \subseteq \Omega} m(E)$. Subsets with a strictly positive mass are called focal elements. In our case $\Omega$ will be the set of models, and focal elements $E_{\phi}$ will corresponds to sets of models of formulas $\phi$. Usually, the inconsistency of a mass function $m$ is measured by the quantity $m(\emptyset)$. While there are good reasons (by which we mean properties and axioms) to consider it as a reasonable inconsistency measure [1], several authors have discussed alternatives $[1,5,4]$. In this paper, we will not question nor challenge its validity, but will rather increase its expressiveness.

Our discussion does not really depend on the used merging rule between mass functions, except for the fact that the rule should be able to generate some inconsistency, i.e., to produce a non-null mass on $\emptyset$, so we will focus on the standard conjunctive rule. Given two mass functions $m_{1}, m_{2}$, the mass $m_{12}$ on a given set $C$ resulting from the conjunctive rule is

$$
m_{12}(C)=\sum_{A, B \subseteq \Omega, A \cap B=C} m_{1}(A) m_{2}(B) .
$$

Let us now proceed to an example that will serve as a basis and motivation for our discussion.

\footnotetext{
$\overline{1}$ to our knowledge.
} 


\subsection{The example}

Let us consider the two following masses defined on the propositional langage $a, b(\Omega=\{(a, b),(a, \neg b),(\neg a, b),(\neg a, \neg b)\})$ and with focal elements $\phi_{1}=\{a \wedge b\}$ and $\phi_{2}=\{\neg a\}$, which generates $E_{\phi_{1}}=\{(a, b)\}$ and $E_{\phi_{2}}=\{(\neg a, b),(\neg a, \neg b)\}$ :

$$
\begin{aligned}
& m_{1}\left(\phi_{1}=\{a \wedge b\}\right)=\alpha_{1} \quad m_{1}(\top)=1-\alpha \\
& m_{2}\left(\phi_{2}=\{\neg a\}\right)=\alpha_{2} \quad m_{2}(\top)=1-\alpha_{2}
\end{aligned}
$$

Their conjunctive combination gives

$$
\begin{gathered}
m_{12}\left(\phi_{1} \wedge \phi_{2}=\perp\right)=\alpha_{1} \alpha_{2} \\
m_{12}\left(\phi_{1}\right)=\alpha_{1}\left(1-\alpha_{2}\right) \\
m_{12}\left(\phi_{2}\right)=\left(1-\alpha_{1}\right) \alpha_{2} \\
m_{12}(\top)=\left(1-\alpha_{1}\right)\left(1-\alpha_{2}\right)
\end{gathered}
$$

Consider now the situation with three masses

$$
\begin{array}{cc}
m_{1}\left(\phi_{1}=\{a \wedge b\}\right)=\beta_{1} & m_{1}(\top)=1-\beta_{1} \\
m_{2}\left(\phi_{2}=\{\neg a\}\right)=\beta_{2} & m_{2}(\top)=1-\beta_{2} \\
m_{3}\left(\phi_{3}=\{\neg b\}\right)=\beta_{3} & m_{3}(\top)=1-\beta_{3}
\end{array}
$$

whose conjunctive combination, if we restrict ourselves to those intersections leading to the empty set, is

$$
\begin{aligned}
& m_{1 \ldots 3}\left(\phi_{1} \wedge \phi_{2} \wedge \phi_{3}=\perp\right)=\beta_{1} \beta_{2} \beta_{3} \\
& m_{1 \ldots 3}\left(\phi_{1} \wedge \phi_{2}=\perp\right)=\beta_{1} \beta_{2}\left(1-\beta_{3}\right) \\
& m_{1 \ldots 3}\left(\phi_{1} \wedge \phi_{3}=\perp\right)=\beta_{1}\left(1-\beta_{2}\right) \beta_{3}
\end{aligned}
$$

One can see that if $\alpha_{1} \alpha_{2}=\beta_{1} \beta_{2}+\beta_{1}\left(1-\beta_{2}\right) \beta_{3}$, the usual measure of inconsistency $m(\emptyset)$ for belief functions will give the same results, and will be unable to distinguish the two different situations.

However, it could well be argued (and has been in standard logic setting) that the first situation is different from the second one, as from a logical perspective, the consistency of knowledge base $\phi_{1} \wedge \phi_{2} \wedge \phi_{3}$ is usually perceived as different from the one of $\phi_{1} \wedge \phi_{2}$ or $\phi_{1} \wedge \phi_{3}$. It would therefore be necessary to be able to make such a distinction.

In the next section, we make a first proposal as how this could be done by combining inconsistency measures issued from the logic framework to masses of evidence. 


\section{A first step towards a combination}

Approach:

- Assume each initial mass is simple support, with $m\left(\phi_{i}\right)=\alpha_{i}$ being the $i$ th mass

- When combining, keep track of the logical KB produced this way (do not merge all the inconsistent ones into one $m(\emptyset)$ )

- For each such KB, use a normalized logical inconsistency measure to weight the contributions to the emptyset.

Interests:

- a more discriminative notion of conflict

- a refined analysis of the sources of conflict (which formula, with which contribution)

\subsection{A quick review of logical inconsistency measure}

\subsection{A simple proposal to embed logical measure in evidence framework}

\subsection{The case of simple support masses}

\section{Conclusion and discussion}

- Penalty logic and its link with Dempster-Shafer theory

\section{References}

1. Destercke, S., Burger, T.: Toward an axiomatic definition of conflict between belief functions. Cybernetics, IEEE Transactions on 43(2), 585-596 (April 2013)

2. Dubois, D., Prade, H.: A set-theoretic view of belief functions. In: Classic Works of the Dempster-Shafer Theory of Belief Functions, pp. 375-410. Springer (2008)

3. Grant, J., Hunter, A.: Measuring inconsistency in knowledgebases. Journal of Intelligent Information Systems 27(2), 159-184 (2006)

4. Martin, A.: Conflict management in information fusion with belief functions. In: Information quality in information fusion and decision making, pp. 79-97. Springer (2019)

5. Pichon, F., Jousselme, A.L., Abdallah, N.B.: Several shades of conflict. Fuzzy Sets and Systems 366, 63-84 (2019)

6. Roquel, A., Le Hégarat-Mascle, S., Bloch, I., Vincke, B.: Decomposition of conflict as a distribution on hypotheses in the framework on belief functions. International journal of approximate reasoning 55(5), 1129-1146 (2014)

7. de Saint-Cyr, F.D.: Penalty logic and its link with dempster-shafer theory. In: Uncertainty in Artificial Intelligence: Proceedings of the Tenth Conference on Uncertainty in Artificial Intelligence, University of Washington, Seattle, July 29-31, 1994. p. 204. Elsevier (2014)

8. Thimm, M.: On the evaluation of inconsistency measures. Measuring Inconsistency in Information 73 (2018) 